\title{
Heterocontrole da fluoretação da água de abastecimento público no Brasil: revisão integrativa
}

\section{Externalcontrol of public supplywater fuoretation in Brazil. integrative review $16 / 12 / 2018$ \\ Data de aprovação: $04 / 12 / 2019$}

Mirian Kuhnen $^{1 *} \mid$ Ramona Fernanda Ceriotti Toassi ${ }^{2}$ | Lucia Ceccato de Lima ${ }^{1}$

DOI: https://doi.org/10.36659/dae.2021.012

ORCID ID

Kuhnen M (D) https://orcid.org/0000-0002-1035-7295
Toassi RFC (D) https://orcid.org/0000-0003-4653-5732

Lima LC (D) https://orcid.org/0000-0002-0760-5913

\section{Resumo}

A fluoretação da água é uma questão de saúde pública, com dimensões complexas e interdisciplinares haja visto que as concentrações variáveis quanto aos valores recomendados podem causar danos à saúde da população. Com objetivo de sistematizar o conhecimento das publicações sobre o heterocontrole da fluoretação da água de abastecimento público no Brasil, foram conduzidas uma revisão integrativa nas bases de dados eletrônicas e uma busca livre na lista de referências de artigos publicados no período de 1990-2016. Baseado nos 55 artigos selecionados foi detectada disparidade regional nas publicações e não-uniformidade metodológica. Verificaram-se oscilações nas concentrações de fluoreto, com tendência à subdosagem, possivelmente explicadas pela rede de distribuição complexa, técnica analítica diferente entre controle interno e externo e falhas no campo operacional. Evidenciaram-se dificuldades na manutenção da concentração ótima de fluoreto nas águas de abastecimento público, justificando o aprimoramento do heterocontrole e de pesquisas que apontem os fatores associados às oscilações dos teores de fluoreto.

Palavras-chave: Fluoretação. Vigilância em saúde. Qualidade da água.

\section{Abstract}

Water fluoridation is a public health issue with complex and interdisciplinary dimensions since varying concentrations of recommended values can cause harm to the health of the population. In order to systematize the knowledge of the publications on the heterocontrol of public water supply fluoridation in Brazil, an integrative review was conducted in the electronic databases and a free search in the list of references of articles published in the period 1990-2016. Based on the 55 articles selected, a regional disparity was detected in the publications, non-uniformity of methodology. There were fluctuations in fluoride concentrations, with a tendency to underdose and possibly explained by the complex distribution network, different analytical technique between internal and external control, and operational failures. It was observed difficulties in maintaining the optimum fluoride concentration in the public water supply, justifying the improvement of the external control and of research that point out the factors associated with oscillations of the fluoride contents.

Keywords: Water fluoridation. Water supply. Water quality control.

\footnotetext{
${ }^{1}$ Universidade do Planalto Catarinense (Uniplac) - Lages - Santa Catarina - Brasil.

${ }^{2}$ Universidade Federal do Rio Grande do Sul (UFRGS) - Rio Grande do Sul - Brasil.

* Autora correspondente: mkauniplaclages.edu.br.
} 


\section{INTRODUÇÃO}

A fluoretação das águas de abastecimento público é tida como uma medida prática, segura, de baixo custo operacional e que não depende do componente individual para sua aplicação, pois sendo inevitável o consumo de água, o benefício ocorre de modo involuntário, como ao preparar os alimentos (NARVAI, 2000a) ou sua ingestão. Além disso, aspectos históricos e epidemiológicos do uso do fluoreto no século XX o consolidam como o principal agente no enfrentamento da doença cárie em todo o mundo, sendo recomendado por mais de 150 organizações de ciência e saúde (NARVAI, 2000a).

O mecanismo pelo qual o fluoreto age no controle da cárie consiste na sua ingestão e retorno para a cavidade bucal por meio de secreção da saliva pelas glândulas salivares. A principal implicação desse método de ação, para que os benefícios da fluoretação possam ser efetivamente alcançados na redução da cárie dentária, depende da sua continuidade, evitando-se interrupções no processo, e a manutenção de teores adequados de fluoreto ativo, de acordo com o preconizado para cada localidade (BRASIL, 2009).

A constatação de que municípios brasileiros não realizavam adequadamente a adição de compostos de fluoreto ao tratamento das águas de abastecimento (NARVAI, 2000a), conforme a Lei Federal $n^{\circ} 6.050$ de 1974 (BRASIL, 1974), fez emergir o heterocontrole.

O princípio que rege o heterocontrole da fluoretação da água de consumo humano consiste em: se um bem ou serviço implica em risco ou representa fator de proteção para a saúde pública, além do controle do processo de produção, distribuição e consumo deve haver controle por outros setores (público ou privado) para a manutenção do padrão de qualidade e proteção da saúde dos indivíduos (NARVAl, 2000a).
Assim, heterocontrole é um monitoramento da fluoretação da água de consumo humano realizado por instituições não envolvidas diretamente no processo de operacionalização da fluoretação, assumindo uma forma de participação social sobre a vigilância da qualidade da água (ELY et al, 20013). O heterocontrole, além de fiscalizar a adequação dos níveis de fluoreto adicionados à água, é um valioso instrumento para garantir ao consumidor o direito às informações sobre a qualidade da água, assegurado por lei (SALIBA et al., 2007).

Globalmente, a fluoretação da água foi introduzida em mais de trinta países, acessível para cerca de 380 milhões de pessoas (em torno de $5,7 \%$ da população mundial) que recebem água artificialmente fluoretada, e mais um adicional estimado de 57,4 milhões que consomem água naturalmente fluoretada em teores adequados à prevenção da cárie (BFS, 2018). Nos EUA, por exemplo, dados de 2014 mostraram que 74,4\% da população, ou um total de cerca $211,4 \mathrm{mi}-$ Ihões de pessoas tiveram acesso à água fluoretada com a meta de alcançar $80 \%$ de cobertura em 2020 (CDC, 2016).

No Brasil, a cobertura da fluoretação das águas de abastecimento público expandiu entre 2000 e 2008 , elevando-se a taxa de cobertura de $67,7 \%$ para $76,3 \%$, uma das mais altas coberturas entre os 10 países mais populosos do planeta, beneficiando 7,6 milhões de pessoas em 4.240 (76,12\%) municípios (FRAZÃO; NARVAI, 2017b).

As experiências pioneiras de heterocontrole da fluoretação no Brasil datam de 1990 (NARVAI, 2000b); decorridas quase três décadas e considerando a importância do controle da qualidade da água, esse artigo objetiva sistematizar o conhecimento das publicações nacionais sobre o heterocontrole da fluoretação da água de abastecimento público e, adicionalmente, discutir a cobertura da vigilância da fluoretação das águas. 


\section{MATERIAL E MÉTODO}

Trata-se de uma revisão integrativa, considerada uma ferramenta ímpar por sintetizar as pesquisas disponíveis sobre determinada temática e direcionar a prática fundamentando-se em conhecimento científico. Seu processo de elaboração segue as seguintes fases: elaboração da pergunta norteadora, busca na literatura, coleta de dados, análise crítica dos estudos incluídos, discussão e interpretação dos resultados e apresentação da revisão integrativa (TAVARES; SILVA; CARVALHO, 2010).

\subsection{Estratégias de busca bibliográficas}

Como método de localizar, avaliar e sintetizar as evidências provenientes de estudos primários publicados em periódicos, foi realizada uma revisão integrativa conduzida nas bases eletrônicas: Literatura Latino-Americana e do Caribe em Ciências da Saúde (LILACS) e Biomedical Journal Literature a serviço da National Library of Medicine (MEDLINE/PubMed). Considerando o período entre as primeiras experiências de heterocontrole, elegeu-se o período de janeiro de 1990 e junho de 2016 para a busca de artigos.

A revisão integrativa foi norteada pela pergunta "Quais as evidências dos estudos de heterocontrole da fluoretação das águas de abastecimento público no Brasil?". Em um segundo momento, buscou-se nos artigos aspectos que respondessem à pergunta: "quais as causas/explicações das oscilações dos teores de fluoreto da água de consumo humano?".
Para as estratégias de busca bibliográfica, utilizaram-se todas as combinações possíveis entre quatro grupos de descritores, intercalados pelo operador booleano AND. O primeiro grupo incluiu os termos "fluoretação", "água" e "monitoramento"; o segundo contemplou "fluoretação", "água" e "análise"; o terceiro "fluoretação", "água" e "heterocontrole”, e, por fim; "fluoretação", "água” e "vigilância". Os descritores também foram pesquisados em seus correspondentes na língua inglesa. A busca limitou-se aos artigos com resumo nas línguas inglesa, portuguesa e espanhola, podendo apresentar textos nas respectivas línguas.

A seleção dos artigos foi realizada em duas etapas. Inicialmente, após a obtenção dos resultados de busca, dois revisores independentes (acadêmicos bolsistas de iniciação científica) leram todos os títulos e resumos, selecionando os estudos relevantes e, em caso de dúvida, um terceiro pesquisador participou da decisão sobre a inclusão do artigo ou não. Considerou-se como critério de inclusão artigos com o objetivo de monitorar a fluoretação da água de abastecimento público no Brasil, excluindo estudos de fluoretação natural de águas, alimentos e de água engarrafada, bem como teses, dissertações, editoriais, ensaios e revisões.

O Quadro 1 sumariza o número de artigos localizados nas bases de dados Medline/PubMed e Lilacs, conforme a combinação dos descritores, localizando 37 artigos que atenderam aos critérios de seleção.

Quadro 1- Número de artigos encontrados nas bases de dados Medline/PubMed e Lilacs com a combinação dos descritores, no período de 1990-2016.

\begin{tabular}{|c|c|c|c|}
\hline Combinação dos descritores & Lilacs & Número de artigos selecionados & 8 \\
\hline Fluoretação + água + monitoramento & 21 & 10 \\
\hline Fluoretação + água + heterocontrole & 25 & 9 & 0 \\
\hline Fluoretação + água + análise & 132 & 4 \\
\hline Fluoretação + água + vigilância & 177 & Número de artigos selecionados \\
\hline Combinação dos descritores & Medline/PubMed & 1 \\
\hline Fluoretação + água + monitoramento & 48 & 1 \\
\hline Fluoretação + água + análise & 533 & 0 \\
\hline Fluoretação + água + heterocontrole & 0 & 15 \\
\hline Fluoretação + água + vigilância & 573 & 0 \\
\hline
\end{tabular}


Na sequência, os artigos foram obtidos na íntegra e os estudos relevantes foram selecionados. Nessa fase, foram analisadas as listas de referências e citações de potencial interesse foram selecionadas pelos mesmos critérios estabelecidos na revisão. Dessa forma, se o título do artigo apresentasse os descritores, eram pesquisados nas bases de dados, ou solicitados ao serviço da biblioteca pelo Comut. A partir das listas de referências dos periódicos e busca manual de periódicos brasileiros não indexados foram selecionados mais 18 artigos que atenderam aos critérios de inclusão.

A análise e a interpretação dos resultados encontrados nos artigos foram organizadas em um quadro, criado no programa Excel, para coletar as seguintes informações: 1) autoria e ano; 2) periódico 3) local de realização da pesquisa; 4) distribuição espacial; 5) laboratório de análise; 6) número de amostras analisadas; 7) critérios de classificação dos teores de fluoreto; 8) pesquisadores/entidades envolvidas; 9) fatores analisados para explicar as oscilações dos teores de fluoreto; 10) método de análise; 11) percentual de amostras com teores adequados de fluoreto; 12) ações de intervenção para melhoria da fluoretação e; 13) recomendações dos estudos.

Para análise geral dos resultados encontrados nos estudos quanto ao percentual de amostras adequadas, foram selecionados os artigos que apresentaram os resultados classificando as amostras segundo os teores ótimos, acima e abaixo do aceitável de fluoreto, com um período de acompanhamento de no mínimo doze meses, independentemente do número de amostras analisadas. Os artigos cujos resultados estavam apresentados apenas na forma de média aritmética não foram selecionados.

\section{RESULTADOS E DISCUSSÃO}

Combinando-se todos os métodos de busca e preenchendo os critérios de inclusão foram selecionados 55 artigos publicados em 38 diferentes periódicos (um internacional) voltados a assuntos de saúde pública e meio ambiente, sendo 17 da área odontológica. As revistas com maior número de publicações foram Caderno de Saúde Pública e Journal of Applied Oral Science (quatro publicações) e, com três publicações, Cadernos de Saúde Pública e a Revista do Instituto Adolfo Lutz, respectivamente.

As instituições responsáveis pela realização das pesquisas de heterocontrole da fluoretação contemplaram 26 universidades, 12 centros de pesquisa e cursos de pós-graduação e, secretarias de saúde municipal e estadual. Os cirurgiõesdentistas especialistas em Saúde Coletiva foram os sujeitos responsáveis pela realização das pesquisas com maior participação, incluindo-se adicionalmente os alunos de graduação e pós-graduação em odontologia e docentes do curso de graduação em odontologia.

No que diz respeito ao local (Município/Estado) de realização do heterocontrole da fluoretação, doze estados abrangem os municípios investigados, e um estudo contemplou as capitais. A região Sudeste se destaca concentrando 30 (54,5\%) estudos, seguida pela região Sul com 12 (21\%), os demais distribuídos nas regiões Nordeste, com sete publicações, e no Centro-Oeste com quatro. Preocupa a disparidade regional dos estudos considerando que na região norte do país houve ausência de publicações.

Estudo da vigilância do fluoreto nas águas de abastecimento público das capitais brasileiras revelou em 2005 que, entre as 29 capitais brasileiras, 17 fluoretavam as águas de abastecimento público e apenas 5 realizaram análise do parâmetro fluoreto. Nove capitais que não fluoretam as águas de abastecimento público estão localizadas no Norte e Nordeste do país, (CESA; ABEGG; AERTS, 2011) o que pode explicar a ausência de estudos de heterocontrole. Se as cidades maiores, mais bem estruturadas, já têm essa deficiência, provavelmente os pequenos municípios padeçam também dessa limitação; conforme Moimaz e Santos (2015), a falta de estrutura 
para os pequenos municípios compromete a realização do heterocontrole.

Em relação à distribuição temporal do período de coleta das amostras de água, as mesmas ocorreram de apenas um dia a dez anos de coleta, e em 28 estudos o período relatado foi acima de um ano. Venturini et al. (2017) consideraram estudos com distribuição temporal acima de quatro meses como de delineamento longitudinal.

É importante considerar o tempo de monitoramento pois, quando o estudo apresenta um número de meses pequeno pode comprometer a avaliação da continuidade da exposição de uma determinada população à água fluoretada, justificando considerar o período de um ano (CECOL, 2011). Para os estudos com objetivo de avaliar se o fluoreto estava presente nas águas de abastecimento pôde ser realizada uma única coleta (CARMO et al., 2010; BERGAMO et al., 2015).

Uma diversidade de laboratórios espalhados pelas regiões Sul e Sudeste foram os responsáveis pelas análises técnicas da concentração de fluoreto, com destaque para o Laboratório do NEPESCO/UNESP e o Laboratório de Bioquímica FOP/UNICAMP.

O número de amostras analisadas variou de 28 a 19.533 entre os estudos. Nota-se que a maior parte dos artigos (55\%) apresentou entre 100 a 1.000 amostras de águas analisadas. O número de amostras está relacionado com o tamanho populacional do município e com o tempo de monitoramento. Cecol (2011) preconiza no mínimo três amostras por mês, de água proveniente de cada sistema de tratamento, independentemente do porte demográfico, durante 12 meses, como o ideal para o heterocontrole da água de consumo humano.

Em relação aos critérios de classificação da concentração de fluoreto, os artigos apresentaram: adequado/inadequado, teores ótimos/acima/ abaixo e os que envolvem risco/benefício. Outros estudos (CORREIA, FERREIRA JÚNIOR, MAIA, 2001; FERREIRA, 1999; MODESTO, 1999; MARMOLEJO, COUTINHO, 2010; BUZALAF, 2002) apresentaram os resultados na forma de média aritmética; no entanto, a utilização exclusiva da média para apresentar os resultados de análise da fluoretação é inadequada. Medidas de tendência central não representam a melhor alternativa para expressar a adequação da fluoretação porque a média oculta a grande variação detectada ao longo do período e dos pontos de coleta (PANIZZI; PERES, 2008).

Nos artigos selecionados da década de 90 (Quadro 2), fica evidente o heterocontrole exercendo o seu papel de fiscalização e motivação para a fluoretação das águas de abastecimento, porém não se apontam fatores associados às oscilações.

Quadro 2- Artigos sobre heterocontrole da fluoretação da água de abastecimento público segundo primeiro autor, ano, periódico, local da pesquisa, distribuição espacial, laboratório, número de amostras analisadas e percentual de amostras adequadas. Brasil, 1990-1999.

\begin{tabular}{|c|c|c|c|c|c|c|c|}
\hline & $1^{\circ}$ Autor/Ano & Periódico & $\begin{array}{l}\text { Local da } \\
\text { pesquisa }\end{array}$ & $\begin{array}{l}\text { Distribuição } \\
\text { espacial }\end{array}$ & Laboratório & $\begin{array}{l}\mathrm{N}^{\circ} \text { de amostras } \\
\text { analisadas }\end{array}$ & $\begin{array}{c}\text { Amostras } \\
\text { adequadas \% }\end{array}$ \\
\hline 1. & $\begin{array}{l}\text { SPADARO et al., } \\
1990\end{array}$ & Rev. Odont. USP & $\begin{array}{l}\text { Região de Ribeirão } \\
\text { Preto (SP) }\end{array}$ & 7 meses & $*$ & $*$ & 10,3 \\
\hline 2. & $\begin{array}{l}\text { ARMONIA et al., } \\
1995\end{array}$ & Rev. Inst. Ciênc. Saúde & São Paulo (SP) & 1 ano & $*$ & 625 & 97,1 \\
\hline 3. & $\begin{array}{c}\text { DANTAS; } \\
\text { DOMINGUES, } 1996\end{array}$ & $\begin{array}{c}\text { Divulgação em saúde } \\
\text { para debate }\end{array}$ & Curitiba (PR) & 4 meses & $*$ & 166 & 53,6 \\
\hline 4. & FERREIRA, 1996 & $\begin{array}{l}\text { Encontro Catarinense de } \\
\text { Odont. em Saúde coletiva }\end{array}$ & 37 municípios (SC) & 3 anos & $*$ & 3.414 & 47,63 \\
\hline 5. & $\begin{array}{l}\text { FERREIRA et al., } \\
1999\end{array}$ & Rev. da APCD & Vitória (ES) & 2 dias & $\begin{array}{c}\text { Laboratório de } \\
\text { Odontopediatria/USP }\end{array}$ & 28 & $\begin{array}{c}0,40 \\
\text { (média) }\end{array}$ \\
\hline 6. & $\begin{array}{l}\text { MODESTO et al., } \\
1999\end{array}$ & RBO & Rio de Janeiro (RJ) & 1 mês & $*$ & 60 & $\begin{array}{c}0,22 \\
\text { (média) }\end{array}$ \\
\hline
\end{tabular}


Na primeira década do ano 2000 (Quadro 3) ocorreu o maior número de publicações (49\%), período também da implantação da Política Nacional de Saúde Bucal (BRASIL, 2004) e expan- são da cobertura da fluoretação das águas de abastecimento público, elevando-se a taxa de cobertura de $67,7 \%$ para $76,3 \%$ (FRAZÃO; NARVAl, 2017b).

Quadro 3 - Artigos sobre heterocontrole da fluoretação da água de abastecimento público segundo primeiro autor, ano, periódico, local da pesquisa, distribuição espacial, laboratório, número de amostras analisadas e percentual de amostras adequadas. Brasil, 2000-2009.

\begin{tabular}{|c|c|c|c|c|c|c|c|}
\hline & $1^{\circ}$ Autor/Ano & Periódico & $\begin{array}{l}\text { Local da } \\
\text { pesquisa }\end{array}$ & $\begin{array}{l}\text { Distribuição } \\
\text { espacial }\end{array}$ & Laboratório & $\begin{array}{l}\mathrm{N}^{\circ} \text { de amostras } \\
\text { analisadas }\end{array}$ & $\begin{array}{l}\text { Amostras } \\
\text { adequadas \% }\end{array}$ \\
\hline 7. & NARVAI, 2000b & $\begin{array}{l}\text { Rev. Bras. Odont. Saúde } \\
\text { Coletiva }\end{array}$ & São Paulo (SP) & 10 anos & $\begin{array}{l}\text { Laboratório de controle de } \\
\text { alimentos da SMA (SP) }\end{array}$ & 6.440 & 80,0 \\
\hline 8. & $\begin{array}{c}\text { CORREIA; FERREIRA } \\
\text { JÚNIOR; MAIA, } \\
2001\end{array}$ & $\begin{array}{l}\text { Pesq. Bras. Odontoped. } \\
\text { Clin. Integr. }\end{array}$ & $\begin{array}{l}\text { Zona Sul Rio de } \\
\text { Janeiro (RJ) }\end{array}$ & 1 mês & $\begin{array}{l}\text { Laboratório de Saúde } \\
\text { Bucal da UFF }\end{array}$ & 52 & $\begin{array}{l}0,063 \\
\text { (média) }\end{array}$ \\
\hline 9. & $\begin{array}{l}\text { PAIANO; FURLAN; } \\
\text { FREITAS, } 2001\end{array}$ & ver. Saúde e Ambiente & Joinville (SC) & 5 anos & $\begin{array}{c}\text { Laboratório de Vigilância } \\
\text { Sanitária de Fluoreto/ } \\
\text { UNIVALI }\end{array}$ & $*$ & $\begin{array}{l}\text { 0,37 a } 0,92 \\
\text { (média) }\end{array}$ \\
\hline 10. & $\begin{array}{c}\text { BUZALAF; } \\
\text { GRANJEIRO, } 2002\end{array}$ & J. Public. Health Dent. & Bauru (SP) & 1 mês & $*$ & 240 & 11,0 \\
\hline 11. & $\begin{array}{l}\text { CORRÊA ELY et al., } \\
2002\end{array}$ & Boletim da Saúde & 497 municípios (RS) & 1 ano & LACEN & 5.207 & 27,39 \\
\hline 12. & MAIA et al., 2003 & Cad. Saúde Pública & Niterói (RJ) & 1 ano & $\begin{array}{l}\text { Laboratório de Saúde } \\
\text { Bucal da UFF }\end{array}$ & 48 & 4,0 \\
\hline 13. & LIMA et al., 2004 & Cad. Saúde Pública & Pelotas (RS) & 2 anos & $\begin{array}{c}\text { Laboratório de Vigilância } \\
\text { Sanitária do fluoreto/ } \\
\text { UNIVALI }\end{array}$ & 764 & 50,0 \\
\hline 14. & SILVA et al., 2004 & Rev. Fac. Odontol. Lins & Lins (SP) & 3 meses & $\begin{array}{l}\text { Laboratório do NEPESCO/ } \\
\text { UNESP }\end{array}$ & 108 & 25,0 \\
\hline 15. & BERNARDES, 2005 & Bioikos & Campinas (SP) & 1 dia & $*$ & 454 & 81,1 \\
\hline 16. & $\begin{array}{c}\text { GESTEIRA; } \\
\text { CâMARA, 2005) }\end{array}$ & Cad. Saúde Coletiva & Salvador (BA) & 1 ano & $*$ & $*$ & 47,0 \\
\hline 17. & MOURA et al., 2005 & Rev. Odont. Cien. & Teresina (PI) & 1 ano & $\begin{array}{c}\text { Laboratório de Bioquimica } \\
\text { FOP/UNICAMP }\end{array}$ & 180 & $\begin{array}{l}0,623 \\
\text { (média) }\end{array}$ \\
\hline 18. & LODI et al., 2006 & J. Appl. Oral. Sci. & Bauru (SP) & 6 meses & $*$ & 238 & 56,0 \\
\hline 19. & $\begin{array}{l}\text { PIVA; TOVO; } \\
\text { KRAMER, } 2006\end{array}$ & $\begin{array}{l}\text { Revista da Faculdade de } \\
\text { Odonto PA }\end{array}$ & $\begin{array}{l}\text { Cachoeira do Sul } \\
\text { (RS) }\end{array}$ & 1 ano & $\begin{array}{l}\text { Laboratório de Análises } \\
\text { Químicas Industriais e } \\
\text { Ambientais da UFSM }\end{array}$ & 104 & 63,4 \\
\hline 20. & $\begin{array}{l}\text { RAMIRES et al., } \\
2006\end{array}$ & Rev. Saúde Pública & Bauru (SP) & 1 ano e 1 mês & $*$ & 737 & 85,0 \\
\hline 21. & $\begin{array}{l}\text { SALIBA; MOIMAZ; } \\
\text { TIANO, } 2006\end{array}$ & J. Appl. Oral Sci. & $\begin{array}{l}40 \text { municípios da } \\
\text { região noroeste } \\
\text { (SP) }\end{array}$ & 6 meses & $\begin{array}{c}\text { Laboratório de NEPESCO/ } \\
\text { UNESP }\end{array}$ & 864 & 38,19 \\
\hline 22. & VIDAL et al., 2006 & Stomatos & Torres (RS) & 7 meses & $\begin{array}{l}\text { Laboratório de Análises } \\
\text { Quimicas Industriais e } \\
\text { ambientais-/UFSM }\end{array}$ & 60 & 43,3 \\
\hline 23. & $\begin{array}{l}\text { AMARAL; SOUSA, } \\
2007\end{array}$ & $\begin{array}{c}\text { Rev. de Odontologia da } \\
\text { UniCid }\end{array}$ & Piracicaba (SP) & 8 meses & $\begin{array}{l}\text { Laboratório de Bioquimica } \\
\text { FOP/ UNICAMP }\end{array}$ & 370 & 70,0 \\
\hline 24. & $\begin{array}{l}\text { AMARAL; WADA; } \\
\text { SOUSA, } 2007\end{array}$ & RFO & Piracicaba (SP) & $\begin{array}{c}1 \text { ano e } 9 \\
\text { meses }\end{array}$ & $\begin{array}{l}\text { Laboratório de Bioquimica } \\
\text { FOP/UNICAMP }\end{array}$ & 630 & 85,0 \\
\hline 25. & SILVA et al., 2007 & Cad. Saúde Pública & $\begin{array}{l}\text { Teresina/Floriano/ } \\
\text { Parnaíba (PI) }\end{array}$ & 1 ano & $\begin{array}{c}\text { Laboratório de Biologia } \\
\text { Bucal/UFPB }\end{array}$ & 576 & 4,3 \\
\hline 26. & TOASSI et al., 2007 & Ciênc. Saúde Coletiva & Lages (SC) & 1 ano & $\begin{array}{c}\text { Laboratório de Vigilância } \\
\text { Sanitária do Fluoreto/ } \\
\text { UNIVALI }\end{array}$ & 120 & 54,2 \\
\hline 27. & $\begin{array}{l}\text { WAMBIER et al., } \\
2007\end{array}$ & UEPG Ci. Biol. Saúde & Ponta Grossa (PR) & 10 meses & $\begin{array}{l}\text { Laboratório Higiene Social } \\
\text { e Análise de água do Dep. } \\
\text { Biologia/UEPG }\end{array}$ & 127 & 33,1 \\
\hline 28. & CATANI et al., 2008 & RGO & $\begin{array}{l}8 \text { cidades de SP/ } \\
1 \text { de Minas e do } \\
\text { Ceará }\end{array}$ & 10 anos & $\begin{array}{c}\text { Laboratório de Bioquímica } \\
\text { FOP/ UNICAMP }\end{array}$ & 3.845 & 63,8 \\
\hline
\end{tabular}


Quadro 3 - Continuação...

\begin{tabular}{|c|c|c|c|c|c|c|c|}
\hline & $1^{\circ}$ Autor/Ano & Periódico & $\begin{array}{l}\text { Local da } \\
\text { pesquisa }\end{array}$ & $\begin{array}{l}\text { Distribuição } \\
\text { espacial }\end{array}$ & Laboratório & $\begin{array}{l}\mathrm{N}^{\circ} \text { de amostras } \\
\text { analisadas }\end{array}$ & $\begin{array}{c}\text { Amostras } \\
\text { adequadas \% }\end{array}$ \\
\hline 29. & $\begin{array}{c}\text { PANIZZI; PERES, } \\
2008\end{array}$ & Cad. Saúde Pública & $\begin{array}{l}\text { Campo Grande } \\
\text { (MS) }\end{array}$ & 10 anos & $\begin{array}{l}\text { Laboratório de Vigilância } \\
\text { do Fluoreto/UNIVALI }\end{array}$ & 989 & $\begin{array}{c}\text { Critério I- } \\
46,0 \\
\text { Critério II- } \\
32,0 \\
\text { Critério III- } \\
43,0\end{array}$ \\
\hline 30. & BELLÉ et al., 2009 & Ciênc. Saúde Coletiva & $\begin{array}{l}\text { Microrregião de } \\
\text { Araçatuba (SP) }\end{array}$ & 3 dias & $\begin{array}{c}\text { Laboratório de Bioquimica } \\
\text { FOP/UNICAMP }\end{array}$ & 90 & 63,5 \\
\hline 31. & $\begin{array}{l}\text { DARÉ; SOBRINHO; } \\
\text { LIBâNIO, } 2009\end{array}$ & Eng. Sanit. Ambient. & $\begin{array}{l}6 \text { municípios da } \\
\text { região centro-sul } \\
(\mathrm{PR})\end{array}$ & 5 anos & $\begin{array}{c}\text { Laboratório I da Direção } \\
\text { Regional de Saúde de } \\
\text { Araçatuba }\end{array}$ & 5.157 & 48,4 \\
\hline 32. & $\begin{array}{l}\text { MORAES et al., } \\
2009\end{array}$ & Ambiência & Oito municípios & 3 meses & $*$ & 219 & 68,0 \\
\hline 33. & SALIBA et al., 2009 & Rev. Odont. Ciência & Noroeste (SP) & 3 anos & $\begin{array}{c}\text { Laboratório de NEPESCO/ } \\
\text { UNESP }\end{array}$ & 864 & 77,4 \\
\hline
\end{tabular}

Fonte: dados da pesquisa.

* Não localizada a informação no artigo.

Quadro 4 - Artigos sobre heterocontrole da fluoretação da água de abastecimento público segundo primeiro autor, ano, periódico, local da pesquisa, distribuição espacial, laboratório, número de amostras analisadas e percentual de amostras adequadas. Brasil, 2010-2016.

\begin{tabular}{|c|c|c|c|c|c|c|c|}
\hline & $1^{\circ}$ Autor/Ano & Periódico & $\begin{array}{l}\text { Local da } \\
\text { pesquisa }\end{array}$ & $\begin{array}{l}\text { Distribuição } \\
\text { espacial }\end{array}$ & Laboratório & $\begin{array}{l}\mathrm{N}^{\circ} \text { de amostras } \\
\text { analisadas }\end{array}$ & $\begin{array}{c}\text { Amostras } \\
\text { adequadas \% }\end{array}$ \\
\hline 34. & CARMO et al., 2010 & Ciênc. Saúde Coletiva & São Luís (MA) & 1 mês & $*$ & 56 & 46,43 \\
\hline 35. & LEIVAS et al., 2010 & Stomatos & Canoas (RS) & 8 meses & $*$ & 176 & 45,5 \\
\hline 36. & $\begin{array}{l}\text { MARMOLEJO, } \\
\text { L.D.G, } 2010\end{array}$ & Rev. Flum. Odontol & Niterói (RJ) & 5 meses & $\begin{array}{c}\text { Laboratório de } \\
\text { Química Analítica/ } \\
\text { UFF }\end{array}$ & 165 & 0,8 (média) \\
\hline 37. & $\begin{array}{l}\text { CESA; ABEGG; } \\
\text { AERTS, } 2011\end{array}$ & Epidemiol.Serv. Saúde & Capitais brasileiras & Não se aplica & $*$ & 1.911 & \\
\hline 38. & $\begin{array}{c}\text { MOTTER et al., } \\
2011\end{array}$ & Rev. Panam. Salud Pública & Curitiba (PR) & $\begin{array}{c}8 \text { anos e } 7 \\
\text { meses }\end{array}$ & $\begin{array}{l}\text { Laboratório } \\
\text { contratado pela } \\
\text { SMS }\end{array}$ & 2.542 & $\begin{array}{c}\text { Eletrométrico: } \\
63,97 \% \\
\text { SPADNS: } 15,05 \%\end{array}$ \\
\hline 39. & $\begin{array}{l}\text { SCORSAFAVA et al., } \\
2011\end{array}$ & Rev. Inst. Adolf Lutz & São Paulo (SP) & 2 anos & $\begin{array}{l}\text { Laboratório do } \\
\text { Instituto Adolf Lutz }\end{array}$ & 6.778 & 87,2 \\
\hline 40. & $\begin{array}{c}\text { MOIMAZ et al., } \\
2011\end{array}$ & Rev. Odont UNESP & Birigui (SP) & 1 ano & $\begin{array}{l}\text { Laboratório de } \\
\text { NEPESCO/UNESP }\end{array}$ & 512 & 44,0 \\
\hline 41. & OLIVATI et al., 2011 & Rev. Odont. Cienc. & Capão Bonito (SP) & 1 ano & $\begin{array}{l}\text { Laboratório de } \\
\text { Bioquímica }\end{array}$ & 120 & 80,8 \\
\hline 42. & SILVA et al., 2011 & ver. Inst. Adolfo Lutz & $\begin{array}{l}\text { Município região } \\
\text { centro-oeste (SP) }\end{array}$ & 5 anos & $\begin{array}{l}\text { Laboratório do } \\
\text { Instituto Adolf Lutz }\end{array}$ & 139 & 62,6 \\
\hline 43. & $\begin{array}{l}\text { PEIXOTO et al., } \\
2012\end{array}$ & Rev. Bras. Promoc. Saúde & Jaguaribara (CE) & 1 ano & $\begin{array}{l}\text { Laboratório de } \\
\text { Biologia Bucal/ } \\
\text { UFPB }\end{array}$ & 72 & $\begin{array}{l}\text { Critério I-47,2 } \\
\text { Critério II-63,9 } \\
\text { Critério III-63,9 }\end{array}$ \\
\hline 44. & $\begin{array}{c}\text { MOIMAZ et al., } \\
2012 a\end{array}$ & Braz. Oral Res. & 29 municípios (SP) & 4 anos & $\begin{array}{l}\text { Laboratório do } \\
\text { NEPESCO/ UNESP }\end{array}$ & 6.862 & 53,5 \\
\hline 45. & $\begin{array}{l}\text { MOIMAZ et al., } \\
2012 b\end{array}$ & Braz. Dent. J. & Araçatuba (SP) & 6 anos & $\begin{array}{l}\text { Laboratório do } \\
\text { NEPESCO/UNESP }\end{array}$ & 591 & 62,7 \\
\hline 46. & $\begin{array}{l}\text { SANTOS et al., } \\
2012\end{array}$ & Rev. Inst. Adolfo Lutz & $\begin{array}{c}\text { São José do Rio } \\
\text { Preto (SP) } \\
\text { Nova Aliança (SP) }\end{array}$ & $\begin{array}{c}\text { janeiro } 2003 \\
\text { e agosto de } \\
2011 \\
13 \text { meses }\end{array}$ & $\begin{array}{l}\text { Centro de } \\
\text { Laboratório } \\
\text { Regional de São } \\
\text { José do Rio Preto-X } \\
\text { (IAL CLR } \\
\text { SJRP-X) }\end{array}$ & 1.050 & $\begin{array}{l}\text { Critério I-53,33 } \\
\text { Critério II-55,71 } \\
\text { Critério I- 23,08 } \\
\text { Critério II-32,31 }\end{array}$ \\
\hline 47. & $\begin{array}{l}\text { MARTINS et al., } \\
2012\end{array}$ & Rev. Odonto da Unesp & $\begin{array}{c}\text { Catolé do Rocha } \\
\text { - PB }\end{array}$ & 1 mês & $*$ & 37 Poços & \\
\hline 48. & SILVA et al., 2013 & APS & Vassouras (MG) & 1 mês & $\begin{array}{l}\text { Química da } \\
\text { Universidade } \\
\text { Severino Sombra }\end{array}$ & 16 & $\begin{array}{l}0,38 \mathrm{mg} / \mathrm{L}^{-1} \\
\text { (média) }\end{array}$ \\
\hline
\end{tabular}

continua... 
Quadro 4 - Continuação...

\begin{tabular}{|c|c|c|c|c|c|c|c|}
\hline & $1^{\circ}$ Autor/Ano & Periódico & $\begin{array}{l}\text { Local da } \\
\text { pesquisa }\end{array}$ & $\begin{array}{l}\text { Distribuição } \\
\text { espacial }\end{array}$ & Laboratório & $\begin{array}{l}\mathrm{N}^{\circ} \text { de amostras } \\
\text { analisadas }\end{array}$ & $\begin{array}{c}\text { Amostras } \\
\text { adequadas \% }\end{array}$ \\
\hline 49. & $\begin{array}{c}\text { MOIMAZ et al., } \\
2013\end{array}$ & J. Appl. Oral Sci. & 40 cidades (SP) & 7 anos & $\begin{array}{l}\text { Laboratório do } \\
\text { NEPESCO/UNESP }\end{array}$ & 19.533 & 51,57 \\
\hline 50. & $\begin{array}{l}\text { BUZALAF et al., } \\
2013\end{array}$ & J. Appl. Oral Sci. & Bauru (SP) & 7 anos & $*$ & 4.641 & 69,0 \\
\hline 51. & $\begin{array}{c}\text { STANCARI; DIAS } \\
\text { JÚNIOR; FREDDI, } \\
2014\end{array}$ & Epidemiol. serv. saúde & $\begin{array}{l}36 \text { Municípios da } \\
\text { Grupo de Vigilância } \\
\text { Sanitária da } \\
\text { Regional XV-Bauru }\end{array}$ & $\begin{array}{l}\text { janeiro de } \\
2002 \text { e junho } \\
\text { de } 2011\end{array}$ & $\begin{array}{c}\text { Laboratório do } \\
\text { Instituto Adolfo } \\
\text { Lutz } \\
\text { de Bauru }\end{array}$ & 8.558 & 62,2 \\
\hline 52. & $\begin{array}{l}\text { BERGAMO et al., } \\
2015\end{array}$ & Braz. Oral Res. & Maringá (PR) & 1 ano & $\begin{array}{c}\text { Laboratório de } \\
\text { Bioquímica FOP/ } \\
\text { UNICAMP }\end{array}$ & 325 & 83,7 \\
\hline 53. & $\begin{array}{c}\text { MOIMAZ; SANTOS, } \\
2015\end{array}$ & Arch. Health. Invest. & Birigui (SP) & 10 anos & $\begin{array}{l}\text { Laboratório do } \\
\text { NEPESCO/UNESP }\end{array}$ & 3.425 & 42,86 \\
\hline 54. & $\begin{array}{c}\text { MOIMAZ; SANTOS, } \\
2015\end{array}$ & Rev. Bras. Pesq. Saúde & $\begin{array}{l}13 \text { Municípios } \\
\text { (DRSII-SP) }\end{array}$ & 1 ano & $\begin{array}{l}\text { Laboratório do } \\
\text { NEPESCO/UNESP }\end{array}$ & 3.552 & 41,0 \\
\hline 55. & BRITO et al, 2016 & Cad. Saúde Coletiva & Passo Fundo (RS) & 1 ano & Não cita & 121 & $\begin{array}{c}21,4 \\
\text { (Cecol) }\end{array}$ \\
\hline
\end{tabular}

Fonte: dados da pesquisa.

* Não localizada a informação no artigo.

Entre os 27 estudos do período 2000-2009 (Quadro 3), 17 mostraram oscilações na concentração de fluoreto na água de abastecimento: NARVAI, 2000a; PAIANO, FURLAN, FREITAS, 2001; BUZALAF; GRANJEIRO, 2002; ELY et al., 2002; MAIA et al., 2003; LIMA et al., 2004; LODI et al., 2006; VIDAL et al., 2006; PIVA, TOVO, KRAMER et al., 2006, AMARAL; SOUSA, 2007; SILVA et al., 2007; TOASSI et al., 2007; WAMBIER et al., 2007, CATANI et al., 2008; PANIZZI; PERES,
2008; DARÉ, SOBRINHO, LIBÂNIO, 2009; MORAES et al., 2009.

No Quadro 5 percebe-se um esforço dos municípios de realizar a fluoretação de forma adequada, em sua maioria com um desempenho superior a $50 \%$ das amostras adequadas atendendo aos padrões legais. No entanto, quando se analisa a inadequação dos teores de fluoreto, observa-se que a falha ocorre por teores baixos de fluoreto, o que pode comprometer a eficácia preventiva contra a cárie.

QQuadro 5 - Artigos selecionados na revisão integrativa sobre heterocontrole da fluoretação da água de abastecimento público segundo os resultados dos teores de fluoreto. Brasil, 1990-2016.

\begin{tabular}{|c|c|c|c|c|}
\hline \multirow{2}{*}{$1^{\circ}$ Autor/Ano } & \multirow{2}{*}{$\mathrm{N}^{\circ}$ de amostras } & \multirow{2}{*}{ Amostras adequadas (\%) } & \multicolumn{2}{|c|}{ Amostras inadequadas (\%) } \\
\hline & & & Amostras abaixo (\%) & Amostras acima (\%) \\
\hline Scorsafava et al. 2011 & 6.778 & 87,2 & 11,6 & 1,2 \\
\hline Amaral et al., 2007b & 630 & 84,94 & 2,86 & 12,2 \\
\hline Olivati et al., 2011 & 120 & 80,8 & 6,7 & 12,5 \\
\hline Saliba et al., 2009 & 864 & 77,4 & 22,6 & - \\
\hline Buzalaf et al., 2013 & 4.641 & 69,0 & 25,8 & 5,3 \\
\hline Moimaz et al., 2012b & 591 & 67,2 & 20,6 & 12,2 \\
\hline Catani et al., 2008 & 3.845 & 63,8 & 19,7 & 16,5 \\
\hline Silva et al., 2011 & 139 & 62,6 & 28,8 & 8,6 \\
\hline Stancari et al., 2014 & 8.558 & 62,2 & 29,4 & 8,4 \\
\hline Toassi et al., 2007 & 120 & 54,2 & 10,0 & 35,8 \\
\hline Moimaz et al., 2012a & 6.862 & 53,5 & 30,4 & 16,1 \\
\hline Santos et al., 2012 & 1050 & 53,3 & 26,5 & 20,2 \\
\hline Moimaz et al., 2013 & 19.533 & 51,57 & 30,53 & 17,90 \\
\hline Daré et al., 2009 & 5.157 & 48,4 & 40,6 & 11,0 \\
\hline Ferreira, 1996 & 3.414 & 47,63 & 38,54 & 13,83 \\
\hline Peixoto et al., 2012 & 72 & 47,2 & 44,4 & 8,3 \\
\hline Moimaz et al., 2011 & 512 & 44,0 & 10,0 & 46,0 \\
\hline Ramires et al., 2006 & 737 & 39,1 & 13,1 & 32,3 \\
\hline
\end{tabular}

Fonte: Dados da pesquisa 
Moraes et al. (2009) detectaram ser comum o fornecimento de água à população com teores de fluoreto abaixo dos valores mínimos estabelecidos como ideais, consoante com Pelletier (2004) no contexto internacional, fato resultado de dificuldades operacionais na manutenção adequada da concentração ótima de fluoreto nas águas de abastecimento público.

A consequência disso é um aumento da relação custo/benefício. Tal gasto decorre da não obtenção dos valores de redução de cárie esperados, associados à compra de compostos químicos, manutenção de equipamento e pessoal qualificado. Isso posto, estaria havendo um desperdício do dinheiro público, pois seriam gastos insumos para implementação e manutenção do programa sem, contudo, que esse investimento pudesse vir acompanhado dos benefícios esperados (CORREIA; FERREIRA JÚNIOR; MAIA, 2001).

Entre os artigos selecionados, destacam-se os que apresentaram delineamento para identificar características dos sistemas responsáveis pelas oscilações da fluoretação. Entre esses estudos estão os de Maia et al. (2003), Daré, Sobrinho e Libânio (2009), Motter et al. (2011) e Moimaz e Santos (2015). Outros 22 estudos citam possíveis fatores que podem ocasionar as oscilações da concentração de fluoreto, conforme Quadro 6.

Quadro 6 - Relação de fatores que podem ocasionar as oscilações da concentração de fluoreto nas águas de abastecimento público em artigos selecionados para revisão integrativa. Brasil, 1990-2016.

\begin{tabular}{|c|c|c|}
\hline $\begin{array}{l}\text { Fator que pode ocasionar as oscilações } \\
\text { da concentração de fluoreto }\end{array}$ & Autor (ano) & Local \\
\hline Problemas com a bomba dosadora manual (modelo) & $\begin{array}{l}\text { Paiano et al. (2001) } \\
\text { Carmo et al. (2010) } \\
\text { Maia et al. (2003) }\end{array}$ & $\begin{array}{l}\text { Joinville (SC) } \\
\text { São Luís (MA) } \\
\text { Niterói (RJ) }\end{array}$ \\
\hline Variação na vazão d'água & Lima et al. (2004) & Pelotas (RS) \\
\hline $\begin{array}{l}\text { Rede de distribuição complexa } \\
\text { (maior número de reservatórios e ETAS) }\end{array}$ & $\begin{array}{l}\text { Buzalaf et al. (2002) } \\
\text { Lima et al. (2004) } \\
\text { Lodi et al. (2006) } \\
\text { Moimaz et al. (2011) } \\
\text { Silva et al. (2011) }\end{array}$ & $\begin{array}{c}\text { Bauru (SP) } \\
\text { Pelotas (RG) } \\
\text { Bauru (SP) } \\
\text { Birigui (SP) } \\
\text { Região centro-oeste (SP) }\end{array}$ \\
\hline $\begin{array}{l}\text { Dificuldade técnico-operacional (graduação, capacitação, } \\
\text { treinamento) }\end{array}$ & $\begin{array}{l}\text { Buzalaf et al. (2002) } \\
\text { Ely et al. (2002) } \\
\text { Maia et al. (2003) } \\
\text { Lodi et al. (2006) } \\
\text { Panizzi et al. (2008) } \\
\text { Peixoto et al. (2012) }\end{array}$ & $\begin{array}{c}\text { Bauru (SP) } \\
497 \text { municípios (RG) } \\
\text { Niterói (RJ) } \\
\text { Bauru (SP) } \\
\text { Chapecó (SC) } \\
\text { Jaguaribara (CE) }\end{array}$ \\
\hline Técnica analítica diferente entre o controle interno e externo & $\begin{array}{c}\text { Buzalaf et al. (2002) } \\
\text { Ely et al. (2002) } \\
\text { Marmolejo; Coutinho (2010) } \\
\text { Motter et al. (2011) } \\
\text { Olivati et al. (2011) }\end{array}$ & $\begin{array}{c}\text { Bauru (SP) } \\
497 \text { municípios (RG) } \\
\text { Niterói (RJ) } \\
\text { Curitiba (PR) } \\
\text { Capão Bonito (SP) }\end{array}$ \\
\hline Falhas na administração pública & Silva et al. (2007) & Teresina/Floriano/Parnaíba \\
\hline Distância entre reservatórios e ETA & Wambier et al. (2007) & Ponta Grossa (PR) \\
\hline Fonte de abastecimento poço artesiano & Bellé et al. (2009) & Campo Grande (MS) \\
\hline IDH baixo do município & Daré et al. (2009) & Microrregião de Araçatuba (SP) \\
\hline Ausência de equipamento, infraestrutura laboratorial e técnica. & $\begin{array}{l}\text { Saliba et al. (2006) } \\
\text { Peixoto et al. (2012) } \\
\text { Moimaz et al. (2015b) }\end{array}$ & $\begin{array}{c}40 \text { municípios (SP) } \\
\text { Jaguaribara (CE) } \\
13 \text { Municípios (SP) }\end{array}$ \\
\hline Fontes naturalmente fluoretada & $\begin{array}{l}\text { Moimaz et al. (2013) } \\
\text { Moimaz et al. (2015a) }\end{array}$ & $\begin{array}{l}40 \text { municípios (SP) } \\
\text { Birigui (SP) }\end{array}$ \\
\hline
\end{tabular}

Fonte: Dados da pesquisa

Quanto às oscilações espaciais na fluoretação, estudo realizado no município de São Luís, Maranhão, mostrou que os bairros periféricos, em geral menos favorecidos economicamente, eram os mais acometidos pela ausência ou subfluore- tação, situação preocupante, visto que muitas vezes essa seria a única forma de obtenção de fluoreto por tais populações, para as quais este tem importância ainda mais evidente na prevenção da cárie (CARMO et al., 2010). 
Estudo realizado no município de Bauru (SP) em relação aos operadores das companhias de tratamento de água mostrou que a maioria deles não possuía graduação na área e foi observada falta de informação sobre os riscos de hiperfluoretação e hipofluoretação. Um dos componentes para a efetivação de um adequado sistema de fluoretação é o técnico operador, que deve comparecer a programas de treinamento mais rigorosos, não só com respeito à própria técnica analítica mas também abordada a relação aos efeitos negativos da falta de controle (BUZALAF et al., 2002).

Ely et al. (2002) abordam a técnica analítica como fator de diferença entre controle interno e externo e posteriormente o estudo de Motter et al. (2011) reforçou essa preocupação, recomendando que o heterocontrole, sempre que possível, fosse implementado com o mesmo método de análise utilizado pela empresa de saneamento.

Ely et al. (2002) e Lodi et al. (2006) apontam como possíveis explicações para as oscilações dos teores de fluoreto o descuido com o rigor da aplicação da técnica para a adição do fluoreto por parte dos técnicos das companhias de água.

Maia et al. (2003) verificaram grandes distorções no sistema operacional executado na ETA que abastece Niterói (RJ) e citaram o problema da bomba dosadora que não possui mecanismo automático de controle da ingestão do ácido como o fator que contribuiu para a variabilidade da concentração de fluoreto no estudo.

Pelotas (RS) tem uma planta de distribuição hidráulica muito complexa e cerca de 11 reservatórios de água suspeitos de variar a dosagem de fluoreto nos pontos de consumo final, em virtude da alteração da vazão durante o tratamento da água encanada. A inconstância dos teores esteve presente e fatores como a falta de treinamento do operador responsável pela fluoretação, problemas no equipamento hidráulico ou variações na vazão podem ser a razão das oscilações (LIMA et al., 2004).
Moura et al. (2005) explicam que apesar de a água de Teresina $(\mathrm{PI})$ ser proveniente de uma única ETA, ocorreram variações na concentração de fluoreto nos diferentes pontos de coleta realizados, aproximadamente, no mesmo horário. Isso pode ser explicado pela velocidade de esvaziamento dos reservatórios distribuídos pela cidade. Os reservatórios que não estão interligados entre si possuem poços de captação de água, no qual é realizada apenas a cloração da água e distribuição à população, não havendo, portanto, a fluoretação.

Fatores como falhas na administração pública, no campo técnico e político, foram responsáveis pelas baixas concentrações de fluoreto em Teresina, Parnaíba e Floriano (PI) e comprometem a credibilidade da fluoretação (SILVA et al., 2007).

Daré, Sobrinho, Libânio (2009) conduziram estudo com delineamento para explicar os motivos das flutuações nos teores de fluoreto e concluíram que há nítida tendência de os sistemas de maior porte e com maior IDH apresentarem percentual elevado de atendimento de fluoretação.

No estudo de Moimaz et al. (2015), os operadores alegaram dificuldades para manter os teores ótimos na faixa de teores de fluoreto recomendados considerada pequena. Convém salientar que foram relatadas comparações com o tratamento da água com cloro, que permite uma maior variabilidade nos teores quando comparado ao fluoreto. Portanto, evidencia-se a importância de maior rigor no controle dos teores de fluoreto na água de abastecimento, com investimentos em equipamentos adequados e calibrados, contratação e treinamento de trabalhadores qualificados, além da manutenção da infraestrutura necessária para a realização e controle do processo de fluoretação das águas.

Em Curitiba-PR (MOTTER et al., 2011) e Ponta Grossa-PR (WAMBIER, 2007), constatou-se que as companhias de tratamento de água utilizam o 
método colorimétrico de análise. As descobertas podem sugerir problemas com a análise do íon fluoreto, considerando que o controle operacional utilizou um método colorimétrico e o controle externo usou um eletrodo íon-específico.

Municípios de pequeno e médio portes podem ter dificuldades em realizar o controle da adição de fluoreto nas águas de abastecimento público em função da falta de infraestrutura laboratorial e técnica (SALIBA; MOIMAZ; TIANO, 2006; PEIXOTO et al., 2012).

Outro aspecto operacional são os reservatórios das cidades. Em Bauru, São Paulo, amostras coletadas em um único dia apresentaram variações. Esse fato dá origem a uma outra hipótese para explicar a variação na concentração de fluoreto observado no mesmo dia para as diferentes áreas do setor e até mesmo em uma mesma área. A ETA tem vários reservatórios no mesmo setor para melhorar a distribuição, manutenção da oferta e também a reparação de equipamentos. Deve-se considerar, também, que cada reservatório tem diferentes capacidades de armazenamento e de consumo. Assim, a água que chega a uma casa na área não foi necessariamente fluoretada no mesmo momento e talvez nem mesmo no mesmo dia, em comparação a uma outra área do setor. Durante o dia, pode haver variações na dosagem de fluoreto durante o processo de fluoretação. Mesmo que essas hipóteses ajudassem a explicar as variações observadas na concentração de fluoreto, não explicam completamente a ocorrência de tantas oscilações em apenas dois dias de coleta. Além disso, o laboratório que controla a fluoretação de todo o sistema de abastecimento de Bauru está localizado nas instalações da ETA, que reforça o controle do processo de fluoretação realizado na estação (BUZALAF, 2002).

Analisando as recomendações/sugestões dos estudos, constata-se unanimidade quanto ao incentivo ao heterocontrole e a implementação de programas de vigilância da fluoretação em todo o Brasil como uma medida para melhorar a qualidade da água de consumo.

Os benefícios da fluoretação das águas de abastecimento público dependem da continuidade da medida ao longo do tempo e da manutenção regular dos teores ótimos do fluoreto (CATANI et al., 2008). Segundo Moimaz et al. (2013), é necessária a criação de programas de medidas de controle e heterocontrole permanentes para garantir a eficácia da fluoretação.

Motter et al. (2011) propõem que o heterocontrole opere de modo ininterrupto, sob responsabilidade de agentes comprometidos com a vigilância da saúde de sua localidade. Moimaz et al. (2011) afirmam que é considerável o número de municípios que não controlam a fluoretação das águas de forma adequada, sendo comprovada a necessidade da correção e do monitoramento de todo o processo. $O$ poder público deve assegurar que o sistema de abastecimento da água fluoretada funcione de forma permanente, eficiente e efetiva.

Peixoto et al. (2012) reforçam a necessidade de a fluoretação ser vista com mais responsabilidade por parte dos representantes políticos e gestores das companhias de abastecimento de água para que haja a qualidade desejada no produto final, garantindo mais investimento em recursos técnicos e humanos e o aprimoramento do sistema de vigilância da qualidade da água.

Panizzi e Peres (2008) realizaram um estudo com intervenção sobre os resultados alterados da fluoretação do município de Chapecó (SC). Tratou-se de uma intervenção político-jurídica realizada pelo sistema de vigilância sanitária da fluoretação das águas de abastecimento público do município, que iniciou com reuniões entre técnicos e dirigentes da Secretaria Municipal de Saúde (SMS) e os responsáveis pela fluoretação, objetivando adequação e manutenção da concentração de fluoreto conforme preconizado para o 
município. Permanecendo inalterada a situação, a SMS apresentou um relatório com análises das concentrações de fluoreto à Promotoria de Justiça/Defesa do Meio Ambiente, que resultou na instauração de procedimento administrativo. Em decorrência, a companhia de abastecimento público de água efetivou medidas de melhoria do sistema e remessa da análise mensal de qualidade da água do município, resultando no arquivamento do processo. A SMS realizou o evento intitulado Fluoretação com Qualidade: Direito de Cidadania como forma de exercer o controle social e tornar público o problema. Sugerem os autores que o heterocontrole da fluoretação não deve se limitar à coleta e análise de dados em um período de tempo, de forma burocrática, mas ser um processo contínuo e permanente.

Entre os artigos selecionados, levantaram-se as sugestões para a melhoria da fluoretação: (I) incentivar municípios a adotar a fluoretação; (II) promover encontros intra e intersetorial; (III) divulgação com periodicidade para instituições de ensino, instância do controle social e à comunidade; (IV) ampliação do debate acerca do controle social; (V) mais responsabilidades por parte dos representantes políticos e gestores das companhias de água; (VI) divulgação mensal dos valores de fluoretação pela companhia de tratamento da qualidade da água; (VII) mais investimentos em recursos técnicos, humanos, administrativos e financeiros; (VIII) aprimoramento da Vigilância em Saúde para que possa desenvolver um monitoramento adequado.

Fazendo um paralelo com a pesquisa VIGIFLUOR (FRAZÃO; NARVAI, 2017), que traçou a cobertura e vigilância da fluoretação das águas em municípios com mais de 50 mil habitantes, o panorama das publicações científicas de heterocontrole apresenta três tendências em relação a cobertura populacional de água fluoretada e sua vigilância, quando se analisa o número de publicações e os locais investigados (Quadro 7). Observam-se estados com boa cobertura de água fluoretada con- centrando o maior número de publicações (SP, RS, RJ, PR, SC, MS, MG, CE, PI, ES e BA); estados com boa cobertura de água fluoretada, mas sem nenhuma publicação (TO, GO, SE, DF, AM, RR); e estados com baixa ou ausência de cobertura de água fluoretada e nenhuma publicação (AL, RO, PA, PE, RN, PB, AC, AP). Mato Grosso (MA) foi exceção, com uma publicação e cobertura populacional de 12,2 \%.

Contudo, apenas $53 \%$ dos municípios fluoretados realizam a vigilância com base em dados de heterocontrole. A situação é melhor nas regiões Sudeste e Sul e muito ruim nas demais regiões, indicando a necessidade urgente da formulação de estratégias para inserir o tema na agenda de todos os gestores da saúde (FRAZÃO; NARVAI, 2017a).

Quadro 7 - Distribuição dos estados brasileiros segundo a cobertura ${ }^{1}$ de água fluoretada e o número de artigos de heterocontrole.

\begin{tabular}{|c|c|c|}
\hline Estado & $\begin{array}{l}\text { População coberta por } \\
\text { água fluoretada }(\%)^{2}\end{array}$ & $\begin{array}{l}\mathrm{N}^{\circ} \text { de artigos de } \\
\text { heterocontrole }\end{array}$ \\
\hline $\mathrm{SP}$ & 86,9 & 27 \\
\hline RS & 88,8 & 6 \\
\hline $\mathrm{RJ}$ & 68,8 & 5 \\
\hline PR & 89,3 & 4 \\
\hline SC & 87,6 & 4 \\
\hline MS & 79,2 & 2 \\
\hline MG & 75,7 & 2 \\
\hline $\mathrm{CE}$ & 62,6 & 2 \\
\hline $\mathrm{PI}$ & 59,9 & 2 \\
\hline ES & 90,9 & 1 \\
\hline BA & 86,2 & 1 \\
\hline MA & 6,8 & 1 \\
\hline TO & 85,9 & 0 \\
\hline GO & 78,7 & 0 \\
\hline $\mathrm{SE}$ & 75,0 & 0 \\
\hline DF & 74,4 & 0 \\
\hline AM & 73,6 & 0 \\
\hline $\mathrm{RR}$ & 61,8 & 0 \\
\hline MT & 12,2 & 0 \\
\hline $\mathrm{AL}$ & 9,9 & 0 \\
\hline RO & 8,8 & 0 \\
\hline PA & 2,6 & 0 \\
\hline $\mathrm{PE}$ & 1,1 & 0 \\
\hline $\mathrm{RN}$ & 0 & 0 \\
\hline PB & 0 & 0 \\
\hline $\mathrm{AC}$ & 0 & 0 \\
\hline $\mathrm{AP}$ & 0 & 0 \\
\hline
\end{tabular}

Fonte: Dados da pesquisa.

${ }^{1}$ Dados do VIGIFLUORETO (FRAZÃO; NARVAI, 2017a).

2 Municípios com mais de 50 mil habitantes, dados de 2014 


\section{CONCLUSÕES}

As pesquisas de heterocontrole no Brasil no período de 1990-2016 ocorreram com maior frequência em municípios de maior cobertura populacional da fluoretação.

As publicações, de modo geral, identificam faIhas na fluoretação da água de consumo humano no Brasil e apontam problemas como: bomba dosadora manual, variação na vazão d'água, rede de distribuição complexa, dificuldade técnico operacional, técnica analítica diferente entre o controle interno e externo, falhas na administração pública, distância entre reservatórios e ETA, fonte de abastecimento poço artesiano, IDH baixo do município, ausência de equipamento, infraestrutura laboratorial e técnica e fontes naturalmente fluoretadas.

Os autores das publicações sugerem a necessidade de implantar medidas de controle para garantir a eficácia da fluoretação, porém não apontam com clareza os fatores associados às oscilações dos teores de fluoreto encontrados nos resultados dos estudos.

Percebe-se um esforço dos municípios, com um empenho superior a $50 \%$ das amostras adequadas atendendo aos padrões legais da concentração de fluoreto. No entanto, a inadequação, na maioria das vezes, refere-se a valores baixos de fluoreto, o que pode comprometer a eficácia preventiva contra a cárie. Os estudos de heterocontrole assumem o papel da vigilância em saúde quando publicam os resultados de municípios, porém, por não apresentarem um padrão metodológico entre os estudos, deixam algumas lacunas.

Evidenciam-se, assim, dificuldades na manutenção da concentração ótima de fluoreto nas águas de abastecimento público, justificando o aprimoramento do heterocontrole. Recomenda-se que os estudos de heterocontrole sejam mais detalhados, destacando a rede de distri- buição, tipo de produto e equipamentos utilizados e técnica analítica para que a identificação de problemas e a adoção de medidas para adequação do processo de fluoretação sejam tomadas, e a população receba águas dentro dos padrões de potabilidade.

De modo geral, a população brasileira está deixando de receber adequadamente os benefícios da fluoretação devido à grande variação na concentração de fluoreto, com indício à subdosagem. Possivelmente há dificuldades operacionais na manutenção adequada da concentração ótima de fluoreto nas águas de abastecimento público, justificando alertar as autoridades brasileiras de saúde pública.

\section{CONTRIBUIÇÃO DOS AUTORES}

Todos os autores contribuíram de forma igualitária.

\section{REFERÊNCIAS}

AMARAL, R.; SOUSA, M. L. Oito meses de heterocontrole da fluoretação das águas de abastecimento público de Piracicaba, São Paulo, Brasil. Rev. de Odontologia da Universidade Cidade de São Paulo, São Paulo, v. 19, n. 2, p. 131-6, 2007.

AMARAL, R. C.; WADA, R. S.; SOUSA, M. L. R. Concentração de fluoreto nas águas de abastecimento público relacionada à temperatura em Piracicaba-SP. RFO, [s.l.], v. 12, n. 3, p. 24-8, 2007. https:// doi.org/10.1590/S1413-81232009000400032

ARMONIA, P. L. et al. Estado atual da fluoração das águas de abastecimento público no município de São Paulo. Rev Inst Ciênc Saúde, [s. l.], v. 13, n. 2, p. 63-66, 1995.

BELLÉ, B. L. L. et al. Análise da fluoretação da água de abastecimento público da zona urbana do município de Campo Grande (MS). Ciênc. saúde coletiva, Rio de Janeiro, v. 14, n. 4, p. 1261-1266, 2009. https://doi.org/10.1590/S1413-81232009000400032

BERGAMO, E. T. P. et al. Fluoride concentrations in the water of Maringá, Brazil, considering the benefit/risk balance of caries and fluorosis. Brazilian Oral Research, São Paulo, v. 29, n. 1, p. 1-6, 2015. https://doi.org/10.1590/1807-3107BOR-2015.vol29.0047

BERNARDES, C. F. Fluoretação da água e consumo humano. Bioikos, [s.l.], v. 19, n. 12, p. 39-43, 2005. 
BFS. THE BRITISH FLUORIDATION SOCIETY. One in a Million. 2018. Disponível em: <https://www.bfsweb.org/>. Acesso em: 10 ago. 2018.

BRASIL. Lei n.6050 de 24 de maio de 1974. Dispõe sobre a fluoretação da água em sistemas de abastecimento quando existir estação de tratamento. Brasília: Diário Oficial da União, p. 6021, 1974.

BRASIL. Portaria n.o 2914, de 12 de dezembro de 2011. Estabelece os procedimentos e responsabilidades relativos ao controle $e$ vigilância da qualidade da água consumo humano e seu padrão de potabilidade, e dá outras providências. Brasília: Diário Oficial da União, 12 dez., 2011.

BRASIL. Ministério da Saúde. Fundação Nacional de Saúde. Departamento de Saúde Ambiental. Departamento de Engenharia de Saúde Pública. Manual de Fluoretação da Água Para Consumo Humano. Brasília: Funasa, 2012. 72 p. Disponível em:<http:// www.funasa.gov.br/site/wpcontent/files_mf/mnl_fluoretacao_2. pdf>. Acesso em: 04 ago. 2018.

BRITO, C. S. de et al. Vigilância da concentração de fluoreto nas águas de abastecimento público na cidade de Passo Fundo - RS. Cad. saúde colet., Rio de Janeiro, v. 24, n. 4, p. 452-459, 2016. https://doi.org/10.1590/1414-462X201600040240

BUZALAF, M. A. R; GRANJEIRO, J. Fluctuations in public water fluoride level in Bauru, Brazil. Journal of public, [s.l], v. 62, n. 3, p 173-76, 2002. https://doi.org/10.1590/1678-7757201302196

BUZALAF, M. A. R. et al. Seven years of external control of fluoride levels in the public water supply in Bauru, São Paulo, Brazil. Journal of Applied Oral Science, Bauru, v. 21, n. 1, p. 92-98, fev., 2013 https://doi.org/10.1590/1678-7757201302196

CARMO, C. D. S. et al. Avaliação da fluoretação da água do sistema de abastecimento público na llha de São Luís, Maranhão, Brasil. Ciênc. saúde colet., Rio de Janeiro, v. 15, n. 1, p. 1835-1840, 2010. https://doi.org/10.1590/S1413-81232010000700096

CATANI, D. B. et al. Dez anos de acompanhamento do heterocontrole da fluoretação da água feito por municípios brasileiros, Brasil, 1996-2006. RGO, Porto Alegre, v. 56, n. 2, p. 151-155, 2008.

CENTER FOR DISEASE CONTROL AND PREVENTION. Division of Oral Health. Water Fluoridation Data Statistics. Atlanta, Georgia, 07 Sep, 2016. Disponível em: https://www.cdc.gov/fluoridation/statistics/index.htm. Acesso em: 10 ago.2018.

CECOL. Classificação de águas de abastecimento público segundo o teor de fluoreto. São Paulo, Faculdade de Saúde Pública da Universidade de São Paulo, 2011. Disponível em: <http://www. cecol.fsp.usp.br/dcms/uploads/arquivos/1398177715_CECOL-USP-ClassificacaoAguasSegundoTeorFluor-DocumentoConsensoTecnico-2011.pdf>. Acesso em: 15 maio 2017.

CESA, K.; ABEGG, C.; AERTS, D. A Vigilância da fluoretação de águas nas capitais brasileiras. Epidemiologia e Serviços de Saúde, Brasília, v. 20, n. 4, p. 547-555, 2011.
ELY, H.C.et al. Heterocontrole do programa de fluoretação de águas no Rio Grande do Sul: a situação no ano de 2002. Bol. da Saúde, [s.l], v.16, n.2, p. 52-69, 2002. http://dx.doi.org/10.5123/ S1679-49742011000400014

ELY, H.C.et al. Vigilância da Saúde Bucal. In: ANTUNES, J. L. F.; PERES, M. P. (Org). Fundamentos de Odontologia. Epidemiologia da Saúde Bucal. 2. ed. São Paulo: Santos, 2013 p. 509-538.

CORREIA, R. P.; FERREIRA JÚNIOR, C. D.; MAIA, L. C. Análise da fluoretação da água de abastecimento público na zona sul do município do Rio de Janeiro. Pesqui. bras. odontopediatria clín. integr, João Pessoa, v. ,n. , p. 17-22, 2001. https://doi.org/10.1590/ S1413-81232009000400032

DANTAS, N. L.; DOMINGUES, J. E. G. Sistema de Vigilância dos teores de fluoreto na água de abastecimento público de Curitiba. Divulgação em saúde para debate, Londrina, v. 13, p. 70-82, 1996.

DARÉ, F.; SOBRINHO, M. D.; LIBÂNIO, M. Avaliação do processo de fluoretação nos sistemas de abastecimento de água da região de Araçatuba, São Paulo. Eng. Sanit. Ambient., [s.l], v. 14, n. 2, p. 173-182, 2009. http://dx.doi.org/10.1590/S141341522009000200005

FERREIRA, H. C. et al. Avaliação do teor de fluoreto na água de abastecimento público do município de Vitória-ES. Rev. assoc. paul. cir., São Paulo, v. 53, n. 6, p. 455-456, 1999.

FERREIRA, R. Fluoretação das águas de abastecimento público no Estado de Santa Catarina nos anos de 1994, 1995 e 1996. In: II Encontro Catarinense de Odontologia em Saúde Coletiva. Anais.. Florianópolis: Secretaria Municipal de Desenvolvimento Social/ Universidade Federal de Santa Catarina, p. 37-41, 1996.

FRAZÃO, P.; NARVAI, P. C. Cobertura e vigilância da fluoretação da água no Brasil: municípios com mais de $\mathbf{5 0}$ mil habitantes. São Paulo: Faculdade de Saúde pública da USP, 2017a. p.206. Disponível em http://wwwwlivrosabertos.sibi.usp.br/portaldelivrosUSP/catalog/book/181. Acesso em: 10 jun. 2018.

FRAZÃO, P.; NARVAI, P. C. Fluoretação da água em cidades brasileiras na primeira década do século XXI. Rev. Saúde Pública, São Paulo, v. 51, n. 47, p. 1-11, 2017b. https://doi.org/10.1590/ s1518-8787.2017051006372

FRAZÃO, P.; PERES, M. A.; CURY, J. A. Qualidade da água para consumo humano e concentração de fluoreto. Rev. Saúde Pública, São Paulo, v. 45, n. 5, p. 964-973, 2011. https://doi.org/10.1590/ S0034-89102011005000046

GESTEIRA, C.; CÂMARA, V. Um estudo sobre a fluoretação em água de abastecimento público no município de Salvador, Estado da Bahia, Brasil. Cad. saúde colet, Rio de Janeiro, v. 13, n. 1, p. 185-194, 2005.

KUHNEN, M. et al. Qualidade da água tratada: avaliação dos teores de fluoreto em 10 anos de heterocontrole no município de Lages, Santa Catarina, Brasil. Visa em Debate: Sociedade, Ciência 
Tecnologia, [s.l], v. 5, p. 91-96, 2017. https://doi.org/10.22239/ 2317-269x.00833

LALUMANDIER, J. A. et al. US Drinking Water: Fluoridation Knowledge Level of Water Plant Operators. Journal of Public Health Dentistry, Raleigh , v. 61, no. 2, p. 92-98, 2001. https:// doi.org/10.1111/j.1752-7325.2001.tb03372.x

LEIVAS, L. L. et al. Heterocontrole da fluoretação das águas de abastecimento público do Município de Canoas/RS. Stomatos, [s.l], v. 16, n. 30, p. 11-20, 2010.

LIMA, F. G. et al. Vinte e quatro meses de heterocontrole da fluoretação das águas de abastecimento público de Pelotas, Rio Grande do Sul, Brasil. Cad. saúde pública, Rio de Janeiro, v. 20, n. 2, p. 422-429, 2004

LODI, C. S. et al. Fluoride concentration in water at the area supplied by the Water Treatment Station of Bauru, SP. Journal of Applied Oral Science, [s. I.], v. 14, n. 5, p. 365-370, 2006. https:// doi.org/10.1590/S1678-77572006000500012

MCDONAGH, M. S. et al. Systematic review of water fluoridation. BMJ, [s. l.], v. 321, n. 7265 , p. 855-859, 2000. https://doi. org/10.1136/bmj.321.7265.855

MAIA, L. C. et al. Controle operacional da fluoretação da água de Niterói, Rio de Janeiro, Brasil. Cad. saúde pública, Rio de Janeiro, v. 19, n. 1, p. 61-67, 2003. https://doi.org/10.1590/S0102$311 \times 2003000100007$

MARMOLEJO, L.D.G; COUTINHO, T. C.L. Heterocontrole da fluoretação da água de abastacimento público em Niterói, RJ, Brasil no período de novembro de 2008 a março de 2009. Rev. Fluminense de Odontologia, Rio de Janeiro, n. 33, p. 34-39, 2010.

MARTINS, E. T. L; FORTE, F. D. S.; SAMPÁIO, F. C. Mapeamento dos teores residuais de fluoreto de águas da zona rural do sertão nordestino do Brasil. Rev. Odontol UNESP, [s.l], v. 41, n. 3, p. 147-153, 2012.

MODESTO, A. et al. Avaliação da concentração de fluoreto na água de abastecimento público do município do Rio de Janeiro. RBO, [s.l.], v. 56, n. 5, p. 217-221, 1999.

MOIMAZ, S. A. . et al. Water fluoridation in 40 brazilian cities: 7 year analysis. J. Appl. Oral Sci. , [s.l], v. 21, no. 1, p. 13-9, 2013. https://doi.org/10.1590/1678-7757201302280

MOIMAZ, S. A. S. et al. Fluoretação das águas de abastecimento público em um município com diferentes fontes de captação. Rev. Odontol. UNESP, São Paulo, v. 40, n. 5, p. 203-207, 2011. Disponível em: <http://hdl.handle.net/11449/133368>.

MOIMAZ, S. A. S. et al. Social Dentistry External control of the public water supply in 29 Brazilian cities. Braz. Oral Res., [s.l], v. 26, no. 1, p. 12-8, 2012a. https://doi.org/10.1590/S180683242012000100003

MOIMAZ, S. A. S. et al. Fluoride concentration in public water supply: 72 months of analysis. Brazilian Dental Journal, [s.l], v.
23, n. 4, p. 451-456, 2012b. https://doi.org/10.1590/S010364402012000400024

MOIMAZ, S. A. S. et al. Dificuldades enfrentadas no processo de fluoretação das águas de abastecimento público. Rev. Bras. Pesq. Saúde, Vitória, v. 17, n. 1, p. 87-94, $2015 a$.

MOIMAZ, S. A.; SANTOS, L. F. DOS S. Estudo longitudinal da fluoretação das águas em município com complexa rede de distribuição: dez anos de estudo. Arch. Health Invest., Araçatuba, v. 4, n. 45, p. 11-16, 2015. Disponível: https://archhealthinvestigation. com.br/ArcHI/article/view/925

MORAES, J. et al. Determinação do índice de fluoreto em águas de abastecimento público em municípios da região centro-sul do Paraná. AMBIÊNCIA, [s.l.] v. 5, n. 2, p. 233-246, 14 nov. 2009.

MOTTER, J. et al. Análise da concentração de fluoreto na água em Curitiba, Brasil: comparação entre técnicas. Rev. Panamericana de Saúde Pública, [s.l.], v. 29, n. 4, p. 120-125, 2011.

MOURA, M. de et al. Avaliação longitudinal da fluoretação da água de abastecimento público de Teresina-Piauí. Rev. Odonto Cien., [s.l.], v. 20, n. 48, p. 132-136, 2005.

NARDIN, B. M. Estudo comparativo de diferentes metodologias analíticas para a determinação de fluoreto. Monografia (Licenciatura em Química). Universidade Estadual Paulista Júlio De Mesquita Filho, Bauru, 2016. Disponível em: https://repositorio. unesp.br/bitstream/handle/11449/136581/000859795.pdf?sequence=1. Acesso em: 15 jul. 2018.

NARVAI, P. Cárie dentária e fluoreto: uma relação do século XX. Ciênc. saúde colet., Rio de Janeiro, v. 5, n. 2, p. 381-392, 2000a.

NARVAI, P. C. Fluoretação da água: heterocontrole no município de São Paulo no período 1990-1999. (2):50-56. Rev. bras. odonto em saúde colet.,[s.l], v. 2, p. 50-56, 2000 b.

OLIVATI, F. N. et al. Quality of drinking water fluoridation of Capão Bonito, SP, Brazil, evaluated by operational and external controls. Revista Odonto Ciência, [s.l], v. 26, n. 4, p. 285-290, 2011. https:// doi.org/10.1590/S1980-65232011000400002

PAIANO, H. M. A.; FURLAN, A.; FREITAS, S. F. T. Fluoretação da água de abastecimento em Joinville, de 1994 a 1999. Rev. Saúde e Ambiente, [s.l] v. 2, n. 1/2, p. 41-47, 2001.

PANIZZI, M.; PERES, M. A. Dez anos de heterocontrole da fluoretação de águas em Chapecó, Estado de Santa Catarina, Brasil. Cad. Saúde Pública, Rio de Janeiro, v. 24, n. 9, p. 2021-2031, 2008. https://doi.org/10.1590/S0102-311X2008000900008

PEIXOTO, D. F. et al. Heterocontrole da fluoretação da água de abastecimento público do município de Jaguaribara, Ceará, Brasil. Rev. Bras. Promoç. Saúde, [s.l], v. 25, n. 1, p. 271-277, 2012. https://doi.org/10.1590/1413-812320182311.24712016

PELLETIER, A. R. Maintenance of Optimal Fluoride Levels in Public Water Systems. Journal of Public Health Dentistry, [s. I.], v. 64, n. 
4, p. 237-239, 2004. https://doi.org/10.1111/j.1752-7325.2004. tb02759.x

PIVA, F.; TOVO, M. F.; KRAMER, P. F. Fluoretação da água de abastecimento público do Município de Cachoeira do Sul-RS. Rev. da Faculdade de Odonto, [s.l], v. 47, n. 2, p. 29-32, 2006.

RAMIRES, I. et al. Heterocontrole da fluoretação da água de abastecimento público em Bauru, SP, Brasil. Rev. Saúde Pública, São Paulo, v. 40, n. 5, p. 883-889, 2006. https://doi.org/10.1590/ S0034-89102006005000005

RAWSON, K. G.; DITMYER, M. M. Distance from source and fluoride concentrations in municipal water supply. Journal of Investigative and Clinical Dentistry, [s.l] v. 4, n. 1, p. 49-53, 2013. https:// doi.org/10.1111/j.2041-1626.2012.00138.x

SALIBA, N. A.; MOIMAZ, S. A. S.; TIANO, A. V. P. Fluoride level in public water supplies of cities from the northwest region of São Paulo State, Brazil. Journal of Applied Oral Science, [s.l], v. 14, n. 5, p. 346-350, out. 2006. https://doi.org/10.1590/S16787757200600050000

SALIBA, N. A. et al. A importância do heterocontrole da fluoretação das águas de abastecimento público. Rev. Fac. Odontol. Lins (Impr.), [s.l], v. 19, n. 2, p. 45-49, 2007.

SALIBA, N. A. et al. Fluoride content monitoring of the public water supply of the Northwest area of the state of São Paulo, Brazil: 36-month analysis. Rev. odonto ciênc, [s. I.], v. 24, n. 4, p. 372 376, 2009.

SANTOS, C. C. M. et al. Avaliação da concentração de fluoreto nas águas de abastecimento público: estudo retrospectivo e de heterocontrole. Revista do Instituto Adolfo Lutz, São Paulo, v. 71, n. 3, p. 507-513, 2012.

SCORSAFAVA, M. A. et al. Avaliação da qualidade da água de abastecimento no período 2007-2009. Rev. Inst Adolfo Lutz, São Paulo, v. 70, n. 3, p. 395-403, 2011.

SILVA, F. S. J. F. et al. Heterocontrole do teor de fluoreto na água de abastecimento público do município de Lins/SP. Rev Fac Odontol Lins, [s. l.], v. 16, n. 1, p. 22-28, 2004.
SILVA, J. S. da et al. Heterocontrole da fluoretação das águas em três cidades no Piauí, Brasil. Cad. Saúde Pública, Rio de Janeiro, v. 23, n. 5, p. 1083-1088, 2007. https://doi.org/10.1590/S0102$311 \times 2007000500010$

SILVA, M. A. M. da et al. O teor de fluoretos na água de consumo no ambiente escolar e a perspectiva de controle da cárie dentária. Rev. APS, Juiz de Fora, v. 16, n. 4, p. 429-436, 2013.

SILVA, R. A. da et al. Monitoramento da concentração de íons fluoreto na água destinada ao consumo humano proveniente de um município com diferentes sistemas de abastecimento público. Rev. Instituto Adolfo Lutz, São Paulo, v. 70, n. 2, p. 220-224, 2011.

SPADARO, A.C et al. Avaliação do teor de fluoreto na água de abastecimento de cidades na região de Riberão Preto. Rev. Odonto USP, São Paulo, v. 4, n. 3, p. 252-255, 1990.

STANCARI, R. C. A.; DIAS JÚNIOR, F. L.; FREDDI, F. G. Avaliação do processo de fluoretação da água de abastecimento público nos municípios pertencentes ao Grupo de Vigilância Sanitária XV-Bauru, no período de 2002 a 2011. Epidemiologia e Serviços de Saúde, Brasília, v. 23, n. 2, p. 239-248, 2014.

TAVARES, M. S.; SILVA, M. D. DA; CARVALHO, R. DE. Revisão integrativa: o que é e como fazer. Einstein, [s.l], v. 8, n. 1, p. 102-6, 2010.

TOASSI, R. F. C. et al. Heterocontrole da fluoretação da água de abastecimento público de Lages, Santa Catarina, Brasil. Ciênc. saúde colet., Rio de Janeiro, v. 12, n. 3, p. 727-732, 2007. http:// dx.doi.org/10.1590/S1413-81232007000300023

VENTURINI, C. et al. Vigilância e monitoramento de fluoretos em águas de abastecimento público: uma revisão sistemática. Ambiente Água-An, Taubaté, v. 11, n. 4, p. 972-988, out./dez. 2016. http://dx.doi.org/10.4136/ambi-agua.1929

VIDAL, S. G. et al. Heterocontrole da fluoretação da água de abastecimento público do minicípio de Torres/RS. Stomatos, cidade, v. 12 , n. 22, p. 5-9, 2006.

WAMBIER, D. S. et al. Análise do teor de fluoreto nas águas de abastecimento público de Ponta Grossa-PR: dez meses de heterocontrole. UEPG Ci. Biol. Saúde, Ponta Grossa, v. 13, p. 65-72, 2007. https://doi.org/10.5212/publicatio\%20uepg.v13i1/2.451 